\title{
The Influence of Friction Stir Welding of Dissimilar AZ31 and AZ91 Magnesium Alloys on the Microstructure and Tensile Properties
}

\author{
N. S. Mohamed and J. Alias* \\ Structural Material and Degradation (SMD) Focus Group \\ Faculty of Mechanical \& Manufacturing Engineering, Universiti Malaysia Pahang, \\ 26600 Pekan, Pahang \\ *Email: juliawati@ump.edu.my \\ Phone: +6094246277; Fax: +6094246222
}

\begin{abstract}
Joining of magnesium alloys was successfully performed by friction stir welding (FSW) technique. This study was aimed in characterizing the microstructure developed after the FSW and its influence on the mechanical properties. The developed microstructure was observed by using optical microscopy, from the cross-sectional side of welded sample. In this study, FSWed of two dissimilar magnesium $(\mathrm{Mg})$ alloy sheets with low aluminum (AZ31) and high aluminum (AZ91) content were successfully conducted at varied welding speed of 60,80 and $100 \mathrm{~mm} / \mathrm{min}$ and tools rotational rate of 800,1000 and 1200 $\mathrm{rpm}$. The microstructure consists of fine and equiaxed recrystallized grain structure especially at the stir zones. The result of the tensile test indicated that the grain size variation of the joint showed an effect on the mechanical properties and fracture location of the joint. An increasing trend of hardness profile revealed more amount of dissolution of aluminum at the stir zone. From the result, FSW can be concluded as effective joining technique for dissimilar magnesium alloys and produced a defect free joint.
\end{abstract}

Keywords: Magnesium alloys; friction stir welding (FSW); welding speed; tensile strength; ductility.

\section{INTRODUCTION}

The need for lightweight and increased performance in automobile industry has triggered the research on light metal, especially on magnesium $(\mathrm{Mg})$ and its alloys because magnesium alloy are lightest metallic material with high specific strength [1], low density reduces fuel cost, high specific strength and high specific rigidity [2], good damping properties [3], stiffness, high thermal conductivity, good ductility, good cast ability [4]. The density of magnesium is about $35 \%$ of aluminium and $75 \%$ of that of iron; magnesium becomes an excellent potential as a structural material. Vehicle weight reduction is the most effective way to improve fuel consumption and to reduce $\mathrm{CO}_{2}$ emission. Magnesium can be joining by riveting or welding; however, it is still limited.

Joining of magnesium alloys is complex due to their reactivity and inflammability [3]. Recently, friction stir welding (FSW) a solid state joining technique expanded as a potential technique to join similar and dissimilar metals below melting point. During FSW of magnesium alloy, some processing problem and weld defect can be encountered such as solidification, porosity and metallurgical problem [5]. Friction stir welding works by applying a non-consumable rotating tool with a particularly designed pin and shoulder. The tools then pressed through the joint line between two work piece as shown in Figure 
1 [6]. FSW method is the most efficient and effective joining method because heat produced to soften the material around pin without melting. Joining of Mg alloy by FSW has been reported in literature [7-13] but the information is still insufficient.

In this study FSW was adopted to join dissimilar AZ31 and AZ91 magnesium alloys. The challenges involved in establishing a perfect metallurgical joint between AZ31 and AZ91 Mg alloys. Hardness measurements were carried out across the weld joint and tensile test was conducted to evaluate and observe the joint strength.

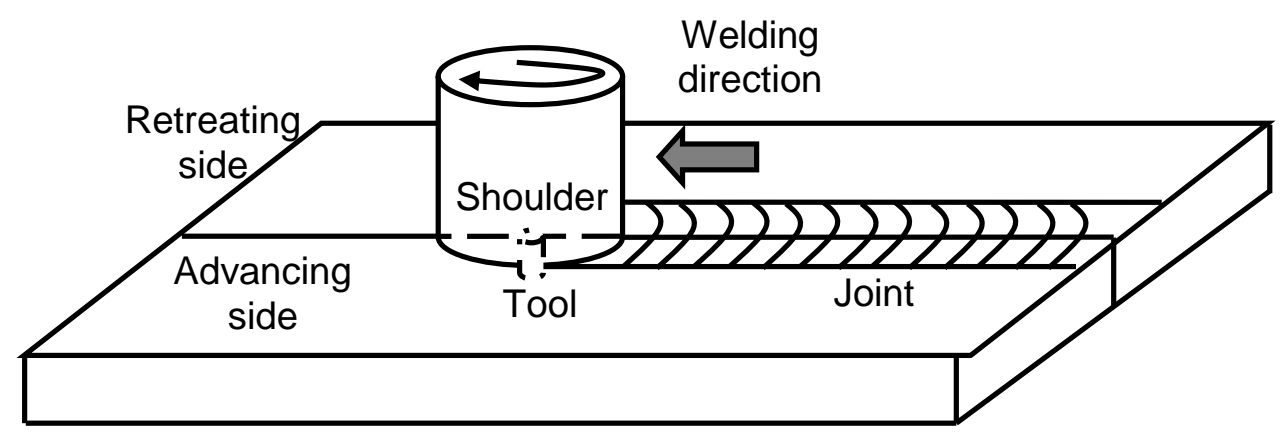

Figure 1. Schematic illustration of friction stir welding process.

\section{EXPERIMENTAL PROCEDURE}

The base metal (BM) was $3 \mathrm{~mm}$ in thickness of AZ31 Mg alloy sheets $(2.75 \% \mathrm{Al}, 0.91 \%$ $\mathrm{Zn}, 0.001 \% \mathrm{Fe}, 0.01 \% \mathrm{Mn}$ and balance $\mathrm{Mg}$ by wt. $\%$ ) and as-cast AZ91 Mg alloy sheets $(8.67 \% \mathrm{Al}, 0.85 \% \mathrm{Zn}, 0.002 \% \mathrm{Fe}, 0.03 \% \mathrm{Mn}$ and balance $\mathrm{Mg}$ by wt. $\%$ ). FSW was carried out using a non-consumable tool made of $\mathrm{H} 13$ tool steel consisting of a shoulder diameter $10.5 \mathrm{~mm}$, pin diameter $3 \mathrm{~mm}$ and pin length $2.80 \mathrm{~mm}$. FSW was carried out by using a universal milling machine as shown in Figure 2(a) and the rotating tool was inserted into the joint at varying welding speed of 60,80 and $100 \mathrm{~mm} / \mathrm{min}$ and tools rotational rate of 800,1000 and $1200 \mathrm{rpm}$ and defect free joint was obtained as present in Figures 2(b) and 2(c). After FSW was done the specimen were cut at different region using wire-cut electric discharge machine (EDM).

Microstructure examination of the sample was carried out on a cross section perpendicular to the welding direction (WD). Specimen for optical microscopy (OM) was mechanically ground and polished down to 0.04 micron and etched in a solution of $10 \mathrm{~g}$ picric acid, $175 \mathrm{ml}$ acetic acid, and $25 \mathrm{ml}$ distilled water. Micro-hardness measurements were carried out by Vickers indentation method across the centerline cross-section perpendicular to the WD by applying $500 \mathrm{~g}$ load for $10 \mathrm{~s}$. Sub-size tensile specimens as shown in Figure 3 with a gauge length of $100 \mathrm{~mm}$, a width of $6 \mathrm{~mm}$, and thickness of 3 $\mathrm{mm}$ were cut perpendicular to the welding direction and tested with a strain rate of $1 \times 10^{-3} \mathrm{~s}^{-1}$ by using a universal testing machine and the specimens were prepared as per ASTM E8/E8M-11 standard. 


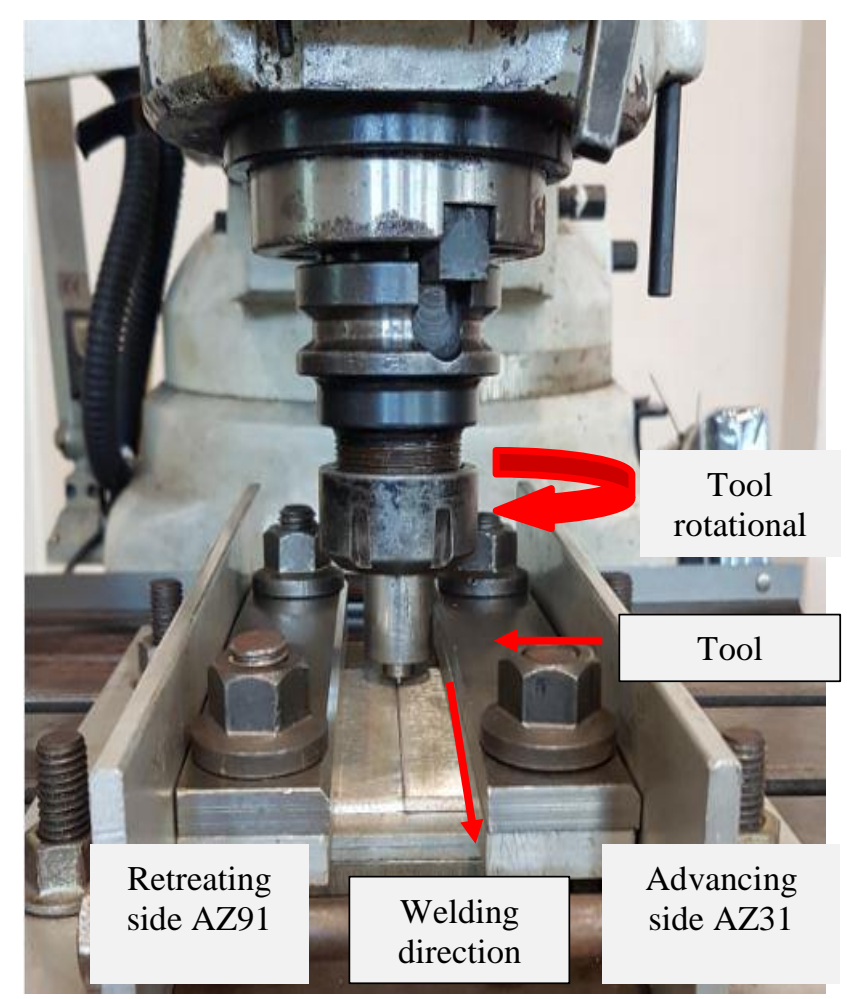

(a)

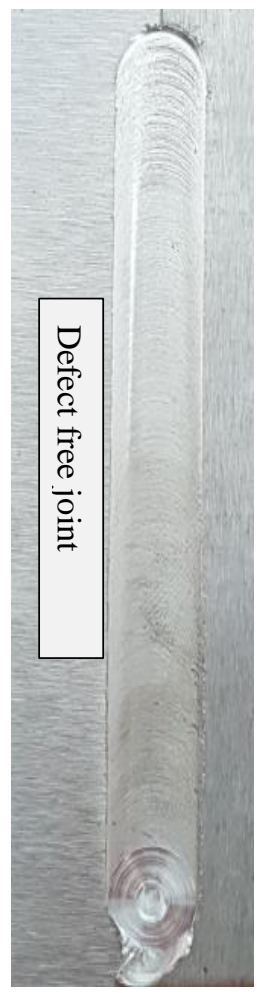

(b)

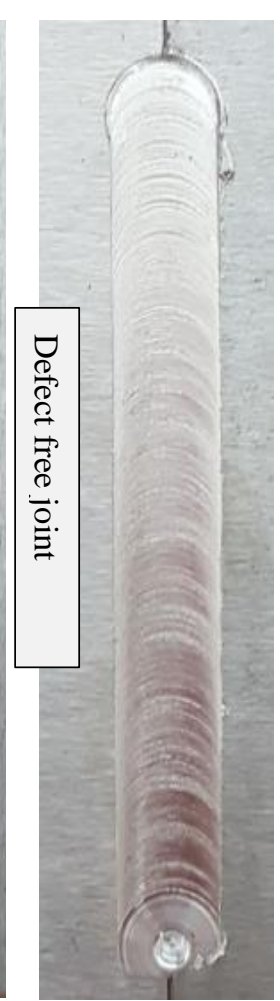

(c)

Figure 2. Optical images of (a) FSW set up used to join AZ31, and AZ91 Mg alloys, (b), (c) defect free joint of the welded sample.

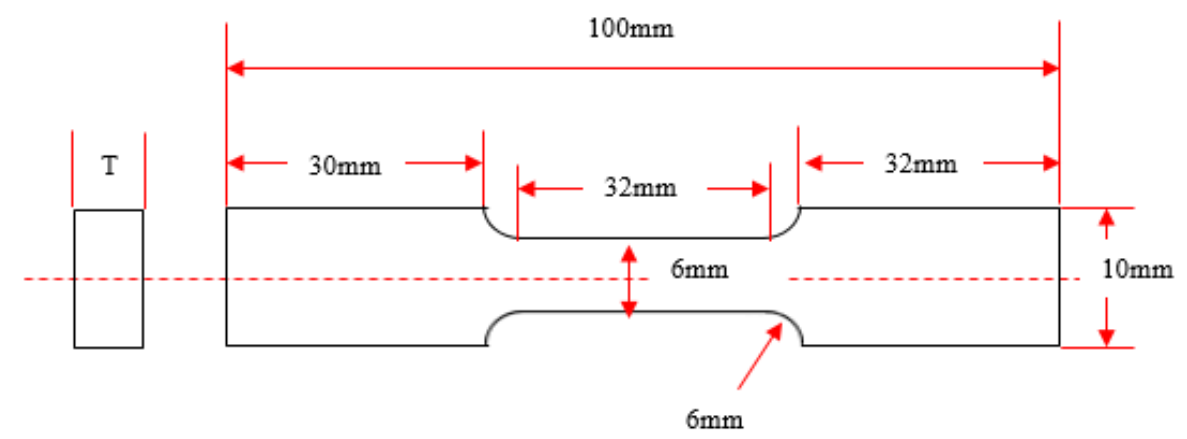

Figure 3. Dimension of tensile test specimen.

\section{RESULT AND DISCUSSION}

\section{Mechanical Properties}

Vickers hardness distribution across the joint centre was measured across the welding direction. The micro-hardness profiles were obtained by measuring from AZ31 to AZ91 base metal of the joint welded at travelling speed of 60,80 and $100 \mathrm{~mm} / \mathrm{min}$, and rotational speed of 800,1000 and $1200 \mathrm{rpm}$. All samples were observed having relatively same trend with an increase in hardness value from AZ31 BM to AZ91 BM for all nine samples. The data of hardness for one of the samples welded at $100 \mathrm{rpm}$ of rotational speed and $800 \mathrm{~mm} / \mathrm{min}$ of travelling speed is provided in Figure 4. The range of hardness value of AZ31 BM was 50 to $70 \mathrm{Hv}$ for all samples. Lower hardness value found in BM 
of AZ31 is due to the uneven and coarse grain structure. The range hardness value at the HAZ of AZ31 BM was 55 to $70 \mathrm{Hv}$ due to the thermal exposure, which causes grain growth. The hardness value started to increase at TMAZ from 60 to $90 \mathrm{Hv}$ and showed fine grain size compared to HAZ. Within the stir (SZ) zone, the hardness value range was 60 to $100 \mathrm{Hv}$, which implies the occurrence of dynamic recrystallisation that caused a dramatic change to the microstructure. Large variations in the hardness values found in the stir zone are expected due to the combined effect oft the fine grain structure of AZ31 and AZ91, and became super-saturated solid solution due to the dissolution of more aluminium by reducing hard $\mathrm{Mg}_{17} \mathrm{Al}_{12}$ phases [3]. The hardness value kept increasing from TMAZ of Z91 to HAZ of AZ91 due to the recrystallisation of microstructure. The highest hardness value dominated by AZ91 BM due to the homogenous of the grain structure containing twins that generated refinement hardening effect.

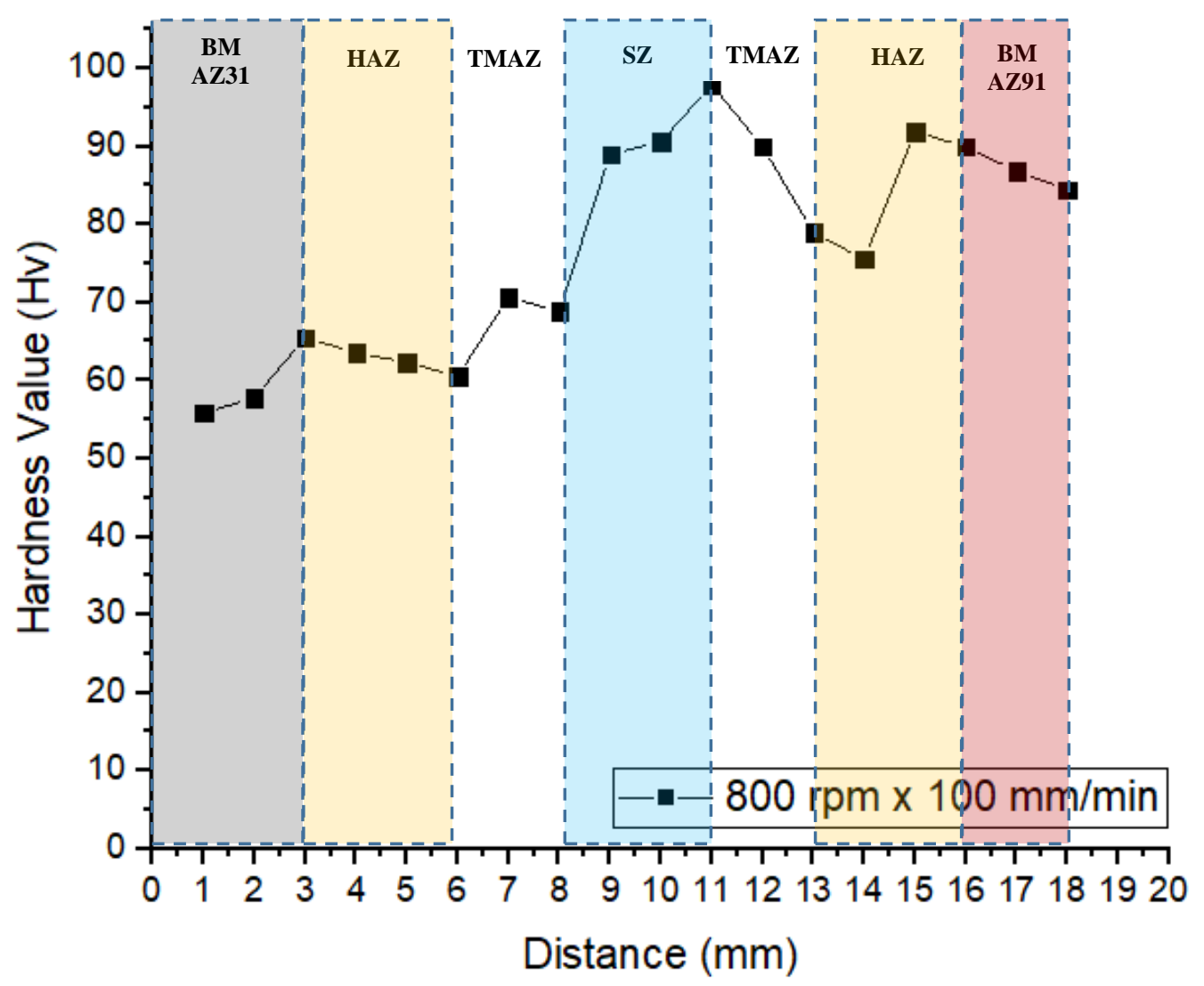

Figure 4. Micro-hardness measurements across the weld joint of AZ31/AZ91 Mg alloys with a rotational speed of $800 \mathrm{rpm}$ and travelling speed of $100 \mathrm{~mm} / \mathrm{min}$, indicating an increase in hardness value from AZ31 BM to AZ91 BM.

From Figure 5, the highest UTS of $251 \mathrm{MPa}$ dominated by sample welded under $1000 \mathrm{rpm}$ rotational speed and $60 \mathrm{~mm} / \mathrm{min}$ feed rate. The strength of joint found to be low than the AZ31 base metal but higher than the AZ91 base metal. From the experiment, the rotational speed of $1000 \mathrm{rpm}$ and $60 \mathrm{~mm} / \mathrm{min}$ feed rate indicated $87 \%$ stronger than the AZ31 BM tensile strength value. Joint efficiency for all welded samples varied from $45 \%$ to $87 \%$ from the BM. The second higher UTS value of $238 \mathrm{MPa}$ revealed by the rotational speed of $1000 \mathrm{rpm}$ and feed rate of $80 \mathrm{~mm} / \mathrm{min}$ and $83 \%$ of strength efficiency, the strength reduce when increasing the feed rate, followed by $800 \mathrm{rpm}$ and $80 \mathrm{~mm} / \mathrm{min}$ 
with the strength of $76 \%$ and UTS value of $217 \mathrm{MPa}$. The medium rotational speed of $1000 \mathrm{rpm}$ and low feed rate of $60 \mathrm{~mm} / \mathrm{min}$ showed higher tensile strength due to the formation and distribution of the fine grain during FSW. After the FSW, the strength decreased inversely proportional to tool rotational speed.

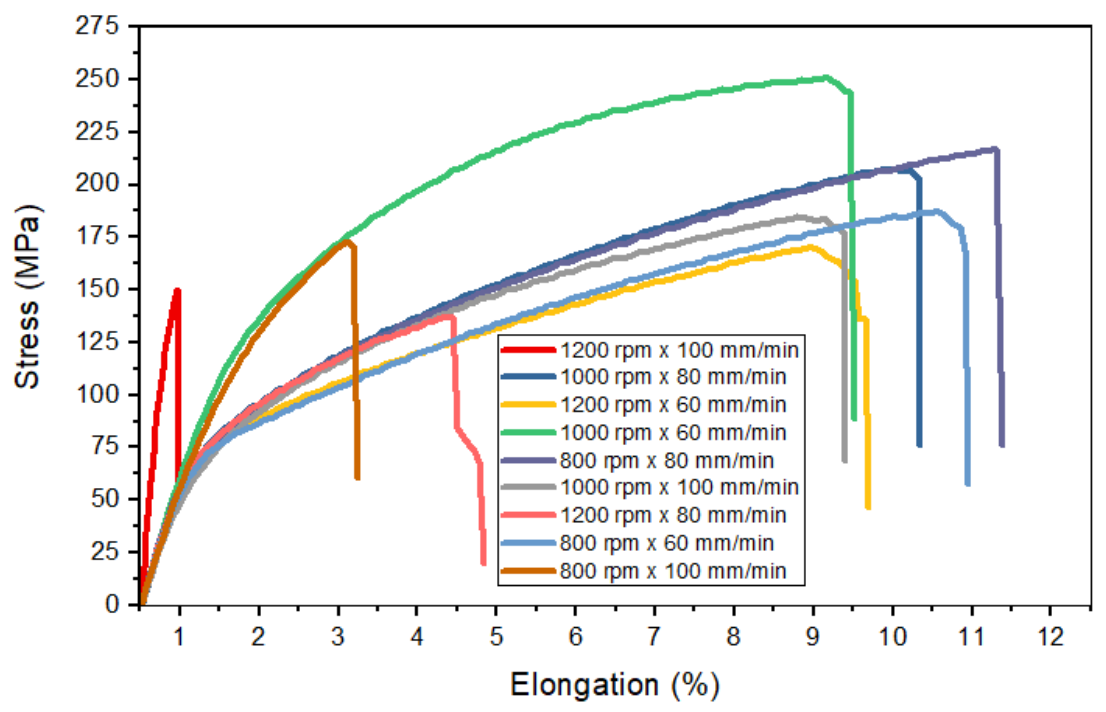

Figure 5. Stress-strain curves of weld joint of AZ31/AZ91 Mg alloys at various welding speeds.

According to the graph, the welding speed of $1200 \mathrm{rpm}$ and rotational speed of 60,100 and $80 \mathrm{~mm} / \mathrm{min}$ shows the top 3 lowest strength with UTS reading of $170 \mathrm{MPa}$, $150 \mathrm{MPa}$ ad $137 \mathrm{MPa}$ while strength efficiency of $47 \%$ to $59 \%$ of the base metal due to an excessive heat generated from the pinning that diminishing the mechanical properties. The lower rotational speed of $800 \mathrm{rpm}$ gives medium UTS reading due to insufficient frictional heat during welding. The microscopic images, as shown in Figure 6 indicated that the welded joints break at HAZ of AZ31 for all samples. The fractured locations correspond to the region with the lowest hardness. The fracture identified as ductile fracture due to necking observed, and the fracture surface indicating excessive plastic deformation takes place during the load test.

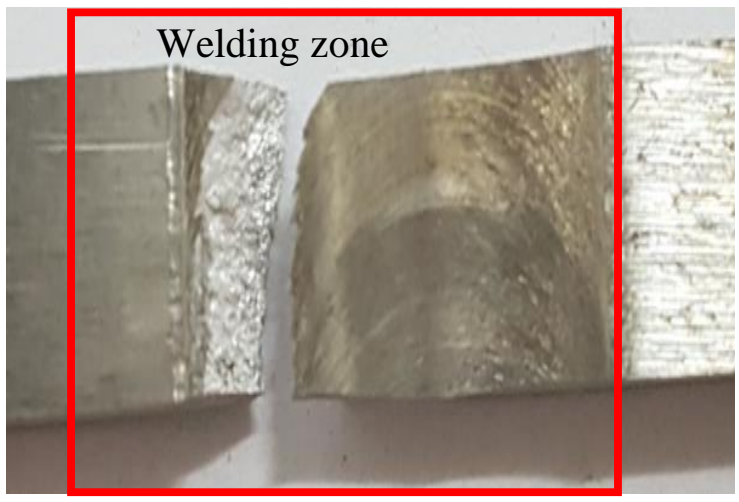

(a) frontside surface

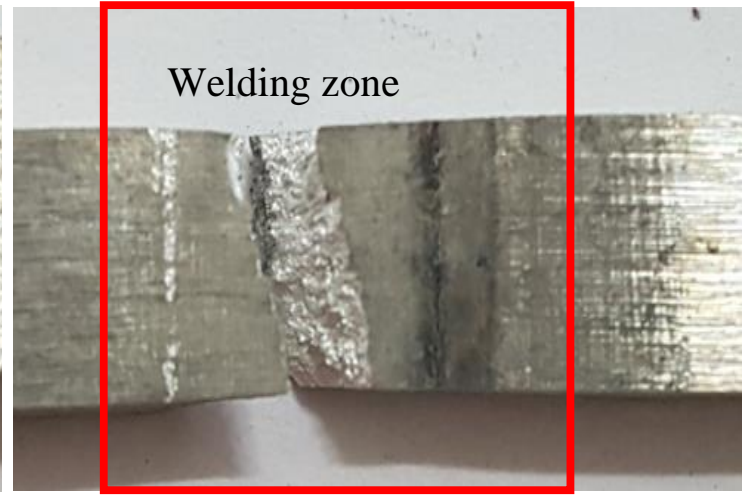

(b) backside surface

Figure 6. Images of fracture at welded zone. 


\section{Microstructure Study}

Cross-sectional micrographs of FSW AZ31 and AZ91 joint are presented in Figure 7. Three microstructural zones were identified in the FSW joint illustrated in (Figures 8), as the stir zone (SZ), thermo-mechanically affected (TMAZ) and heat-affected zones (HAZ). Figure 8(a) shows the deformation twins and elongated grains on microstructures of the AZ91 base metal. The heterogeneity of the BM was due to the heavy deformation by rolling to become $3 \mathrm{~mm}$ thick sheet and incomplete dynamic recrystallisation. The base metal exhibited coarse deformed structures with precipitates being distributed between coarse grains as shown in Figure 8(a) and 8(b). TMAZ shows elongated stretched grain compared to the HAZ of AZ31, which indicated inhomogeneous deformation in the localised region. Absence of dynamic recrystallisation stage was due to insufficient deformation strain and thermal exposure as shown in Figure 8(c) and (d).

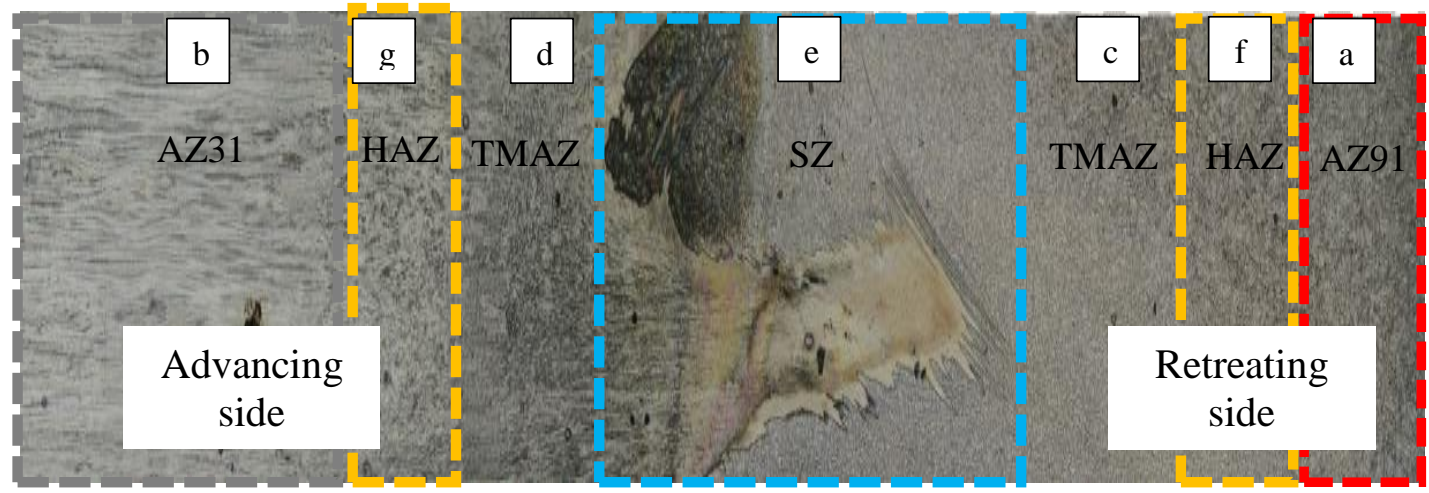

Figure 7. Macrograph of FSW AZ31/AZ91 joint viewed at the cross-section.

The stir zone (SZ) region shows unclear grain structure after etching. The optical micrograph at a certain location in SZ are shown in Figure 8(e) and 8(f). The microstructure of this region contains recrystallised grains with a size of $(10 \pm 1 \mu \mathrm{m})$ with a mixture distribution of fine intermetallic phases, $\mathrm{Al}_{8} \mathrm{Mn}$. Demarcation line in (Figure 7) was observed between AZ31 and AZ91 BM due to the discontinuity in material flow during stirring process. It has been shown that this fine scale intermixing is caused by material being merged into the tool threads during rotation of the pin and shoulder, resulting in the lamellae morphology. The stir zone was found to mix with both AZ31 and AZ91 magnesium alloys but the fraction of AZ91 appeared higher than AZ31 magnesium alloy.

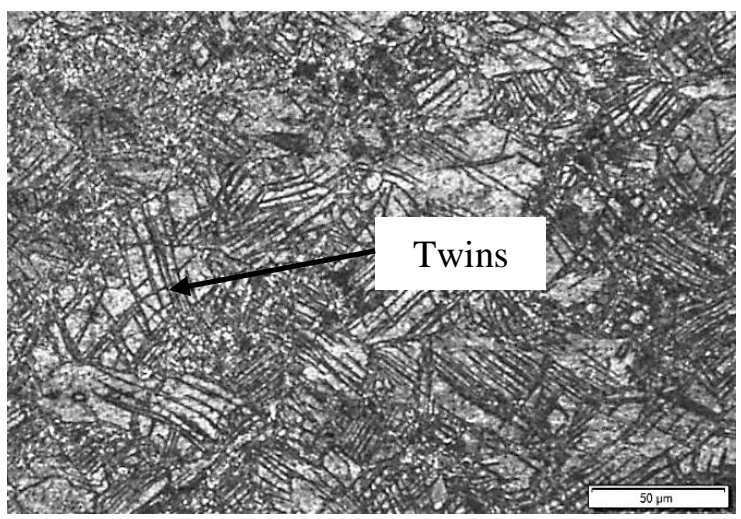

(a)

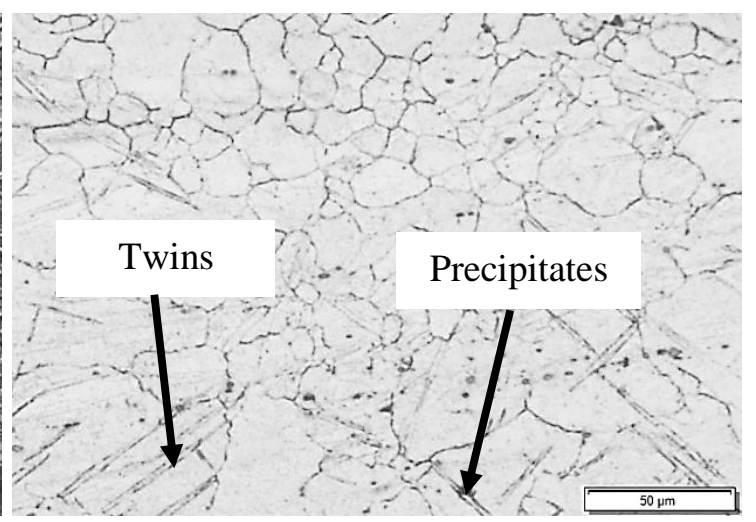

(b) 


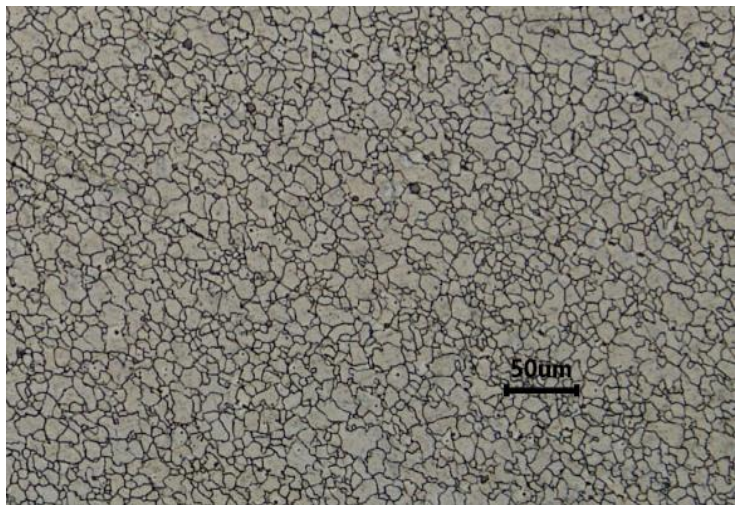

(c)

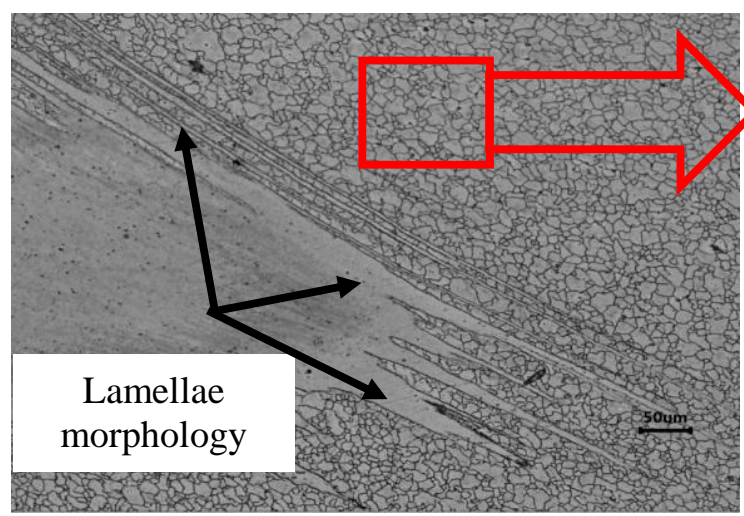

(ei)

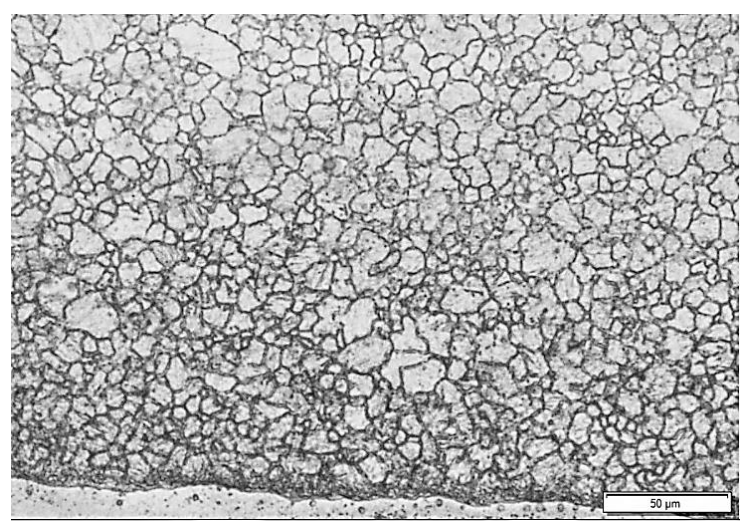

(f)

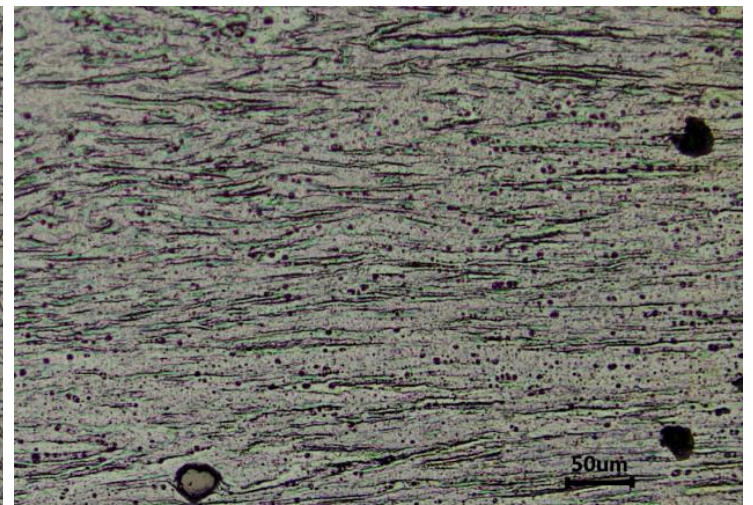

(d)

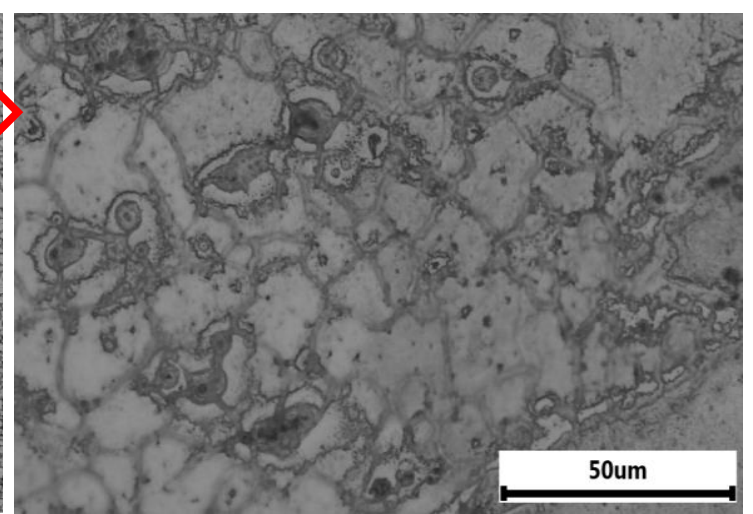

(eii)

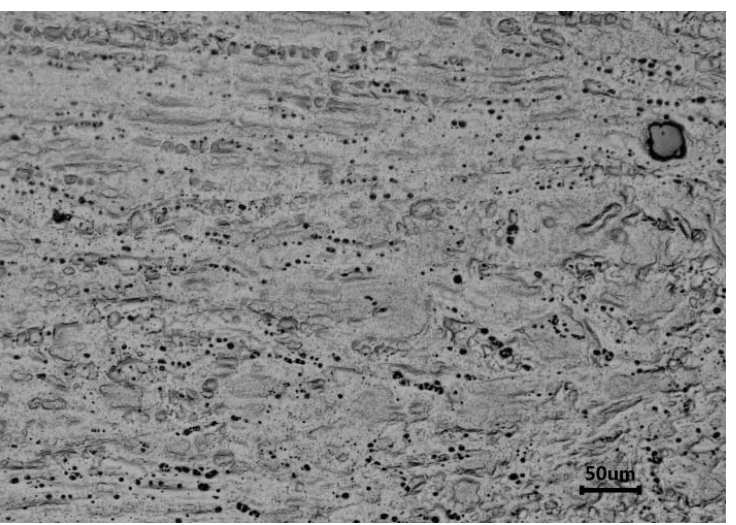

$(\mathrm{g})$

Figure 8. Micrographs of FSW joint AZ31/AZ91 specimens taken at different regions: (a) AZ91 Mg alloy base microstructure, (b) AZ31 Mg alloy base microstructure, (c) TMAZ of AZ31, (d) TMAZ of AZ91, (e) stir zone (SZ), (f) magnified image of stir zone, (g) HAZ of AZ91, (h) HAZ of AZ31

The microstructure of the stir zone (SZ) was characterised by smaller grain size $(10 \pm 1 \mu \mathrm{m})$ and equiaxed grains than the $\mathrm{BM}$, indicating the occurrence of dynamic recrystallisation on both AZ31 and AZ91 due to intense plastic deformation and thermal exposure during FSW (Figure 8(e)). The magnified image in Figure 8(f) shows the joint formation that contained a combination of fine grain. It is well known that the temperature in the SZ during FSW is lower than the melting point but higher than the recrystallisation temperature [3]. Beyond the TMAZ, there is HAZ region in Figure 8(f) and 8(g) which 
shows uneven grain boundary and fracture zone (Figure $8(\mathrm{~g})$ ) which experiences a thermal cycle without any plastic deformation [14].

\section{CONCLUSION}

In this study, AZ31 and AZ91 magnesium alloys were friction stir welded without defect and accompanied by excellent mechanical properties under welding speeds of 60,80 and $100 \mathrm{~mm} / \mathrm{min}$ and at the rotation rate of 600,800 and $1000 \mathrm{rpm}$. The stir zone contains fine and equiaxed grain. Increasing hardness within stir zone is attributed to the grain refinement after the FSW along with solid solution strengthening. Hence FSW can be used as an effective joining technique for dissimilar magnesium alloys for various application.

\section{ACKNOWLEDGEMENT}

This work is supported by the University Malaysia Pahang under RDU160394 grant.

\section{REFERENCES}

[1] Chen J, Fujii H, Sun Y, et al. Effect of grain size on the microstructure and mechanical properties of friction stir welded non-combustive magnesium alloys. Materials Science and Engineering A 2012; 549: 176-184.

[2] Xie GM, Ma ZY, Geng L. Effect of microstructural evolution on mechanical properties of friction stir welded ZK60 alloy. Materials Science and Engineering A 2008; 486: 49-55.

[3] Sunil BR, Kumar GP, Mounika ASN, et al. Joining of AZ31 and AZ91 Mg alloys by friction stir welding. Journal of Magnesium and Alloys 2015; 3: 330-334.

[4] $\mathrm{Hu} \mathrm{H}$, Nie X, Ma Y. Corrosion and Surface Treatment of Magnesium Alloys. Magnesium Alloys - Properties in Solid and Liquid States. Epub ahead of print 2014. DOI: $10.5772 / 58929$.

[5] Singarapu U, Adepu K, Reddy S. Influence of tool material and rotational speed on mechanical properties of friction stir welded AZ31B magnesium alloy. Journal of Magnesium and Alloys 2015; 3: 335-344.

[6] Pagar KR, Wable PAD. Review Paper: Friction Stir Welding (FSW). 2016; 6: 123-129.

[7] Yang J, Xiao BL, Wang D, et al. Effects of heat input on tensile properties and fracture behavior of friction stir welded Mg-3Al-1Zn alloy. Materials Science and Engineering A 2010; 527: 708-714.

[8] Liu D, Xin R, Sun L, et al. Influence of sampling design on tensile properties and fracture behavior of friction stir welded magnesium alloys. Materials Science and Engineering A 2013; 576: 207-216.

[9] Park SHC, Sato YS, Kokawa H. Texture effects on tensile properties in friction stir weld of a magnesium alloy AZ31. 4th International Symposium on Friction Stir Welding 2003; 1-8.

[10] Woo W, Choo H, Prime MB, et al. Microstructure, texture and residual stress in a friction-stir-processed AZ31B magnesium alloy. Acta Materialia 2008; 56: 17011711.

[11] Li WY, Fu T, Hütsch L, et al. Effects of tool rotational and welding speed on microstructure and mechanical properties of bobbin-tool friction-stir welded $\mathrm{Mg}$ 
AZ31. 2014; 64: 714-720.

[12] Paradiso V, Rubino F, Carlone P, et al. Magnesium and Aluminium alloys dissimilar joining by Friction Stir Welding. Procedia Engineering 2017; 183: 239244.

[13] Tuz L, Kołodziejczak P, Kolasa A. Friction stir welding of AZ-91 and AM-Lite magnesium alloys. 7116. Epub ahead of print 2017. DOI: 10.1080/09507116.2011.600036.

[14] Kaushik N, Singhal S, Gahlot P, et al. Experimental investigations of friction stir welded AA6063 aluminum matrix composite. Journal of Mechanical Engineering and Sciences 2018; 12: 4127-4140. 